\title{
Effect of Kelussia odoratissima Mozaffarian on Lipid and Glucose Profile
}

\author{
Mehrdad Shahrani ${ }^{1}$; Azam Asgari ${ }^{1}$; Zahra Abedi Gheshlaghi ${ }^{2}$; Neda Parvin ${ }^{1}$; Parto Nasri ${ }^{3}$; \\ Hedayatollah Shirzad ${ }^{1}$; Mahmoud Rafieian Kopaei ${ }^{1{ }^{*}}$ \\ ${ }_{1}^{1}$ Medical Plants Research Center, Shahrekord University of Medical Sciences, Shahrekord, IR Iran \\ ${ }^{2}$ Nickan Research Institute, Isfahan, IR Iran \\ ${ }_{3}^{3}$ Faculty of Medicine, Isfahan University of Medical Sciences, Isfahan, IR Iran \\ *Corresponding Author: Mahmoud Rafieian Kopaei, Medical Plants Research Center, Shahrekord University of Medical Sciences, Shahrekord, IR Iran. Tel: +98-9131811842, \\ E-mail: rafieian@yahoo.com
}

Received: May 1, 2015; Revised: July 6, 2015; Accepted: July 14, 2015

\begin{abstract}
Background: Flavonoids are a group of polyphenolic compounds with antioxidant properties that help reduce cardiovascular risk factors. Kelussia odoratissima is a flavonoid-containing plant, the effect of which was analyzed on decreasing blood lipid levels in mice. Objectives: The present study was carried out with the aim of determining the anti-hyperlipidemia effects of this herb on mice.

Materials and Methods: In this preclinical study, $70 \mathrm{Balb} / \mathrm{c}$ mice were divided to five 14-member groups and received normal diet, normal diet containing $5 \%$ olive oil, high cholesterol (2\% cholesterol and $5 \%$ olive oil) diet and high cholesterol diet accompanied by Kelussia odoratissima $10 \%$ or $20 \%$ hydro-alcoholic extract. After two weeks, blood samples were taken and cholesterol, triglyceride, low density lipoprotein (LDL), very low density lipoprotein(VLDL), high density lipoprotein (HDL), and fasting blood sugar(FBS) were measured.

Results: In this animal model, the levels of all serum lipids including cholesterol, HDL, VLDL, LDL, triglyceride and FBS had a significant decrease two weeks after the beginning of the study. Moreover, at the same time, in the group that received $20 \%$ hydro-alcoholic extract, the serum levels of cholesterol, HDL and LDL had a significant decrease $(\mathrm{P}<0.05)$.

Conclusions:Kelussia odoratissima might have a desirable effect on serum lipid profile and might have beneficial effects on hyperlipidemic patients.
\end{abstract}

Keywords: Hyperlipidemia; Mice; Human; Triglyceride; Cholesterol

\section{Background}

The relationship between the level of cholesterol and the risk of cardiac diseases was determined in 1948 for the first time. In 1990, interventional studies showed that decrease in the cholesterol level by diet, drugs or surgery reduces the risk of coronary heart disease (CHD). However, taking HMG-CoA (hydroxy-methyl-glutaryl-CoA reductase) reductase inhibitors reduce the amount of LDL- and CHDrelated mortality by up to $30 \%(1,2)$. Among the major consequences of hyperlipidemia, acute pancreatitis and atherosclerosis can be mentioned, and controlling the level of TG can be effective for its control (1-5). However, currently many drugs are used to cure hyperlipidemia; all of them have some side effects (6-9). On the other hand, medicinal plants have generally less side effects and are accepted by people as an alternative treatment since ancient times (1018). Furthermore, recent trends in treating and controlling diseases tend to favor natural antioxidant compounds more than synthetic ones (19-27).

Researches carried out on medicinal herbs have showed hopeful results regarding the treatment of various diseases such as hyperlipidemia $(2,28,29)$, diabetes (30-38), hypertension (39-41) and renal toxicity (26, 42-47).

Kelussia odoratissima Mozaffarian is a medicinal plant that is believed by the people of Chaharmahal and Bakhtiari province to have effective hypolipidemic effects (48). Kelussia odoratissima is one of the genera of the Umbelliferae (Apiaceae) family and has only one species, Kelussia odoratissima that is found only in Iran (49). It is a wild perennial aromatic, rebus, glabrous and erect herb that grows to the height of 120 to 200 centimeters. This sweet-smelling, self-growing monotypic medicinal plant is endemic and is found in a restricted area in west of Iran. Its flowers are hermaphrodites and have a diameter of one to two millimeters. The plant is propagated annually through seeds in natural conditions, during late summer. The aerial parts of Kelussia odoratissima have high nutritional value due to the existence of minerals and vitamins (50). The leaves of this plant are edible and are also used as a wild herb for flavoring and as a drug for curing dyspepsia and rheumatism by the natives of Chaharmahal and Bakhtiari province (51). As mentioned before, Kelussia odoratissima is found in some parts of the Zagros Mountain ranges at the height of 2500 meters above sea level, including Isfahan and Lorestan provinces, and is called "Karafs-e-Bakhtiari" by natives (50-52). In addition, it is traditionally used as a medicinal plant to

Copyright (C) 2015, Shiraz University of Medical Sciences. This is an open-access article distributed under the terms of the Creative Commons Attribution-NonCommercial 4.0 International License (http://creativecommons.org/licenses/by-nc/4.0/) which permits copy and redistribute the material just in noncommercial usages, provided the original work is properly cited. 
treat hypertension, inflammation, ulcers and cardiovascular diseases (53).

There is limited literature on the pharmacological properties of this plant, yet recent studies have shown that the hydro-alcoholic extract of Kelussia odoratissima is sedative (54), which may be due to its bioactive phthalides (55). Shojaei Asadiyeh et al. in 2011 showed that major in gredients of the aerial parts of Kelussia odoratissima are Z-ligustilide and 3-N-butylphthalide (50). Another study also showed that the aerial parts of Kelussia odoratissima contain 23 different valuable components and the major compound is Z-ligustilide (56). Ligustilide and Butylphthalide are the major components of Kelussia odoratissima that have a positive impact on the nervous system, blood pressure and serum cholesterol level $(57,58)$.

\section{Objectives}

Despite the natives' beliefs in the antioxidant effects of $\mathrm{Ke}$ lussia odoratissima and its components, few research projects have been performed on this species. Therefore, the present study was carried out with the aim of determining the anti-hyperlipidemia effects of this herb on mice.

\section{Materials and Methods}

In this pre-clinical study, after obtaining the approval of the ethics committee of the medical university of Shahrekord, 70 Balb/C mice were purchased from the Iran Pasteur institute with a weight range of $24-30$ grams, and were kept in the animal house of Shahrekord medical university for seven days for acclimatization. Then, they were weighted and divided to five 14-member groups. The first group (control) received normal food; the second group received normal food containing 5\% olive oil; the third group was fed a high cholesterol diet (pellets containing 2\% cholesterol and 5\% olive oil); the fourth group received a high cholesterol diet accompanied by Kelussia odoratissima 10\% hydro-alcoholic extract, and finally the fifth group received high cholesterol diet accompanied by Kelussia odoratissima 20\% hydro-alcoholic extract for two weeks. At the end of two weeks, after fourteen hours of fasting, blood samples were taken and lipid factors such as cholesterol, Triglyceride (TG), low density lipoprotein (LDL), very low density lipoprotein (VLDL), high density lipoprotein (HDL) and fasting blood sugar (FBS) were measured by the enzymatic method and spectrophotometry (Pars Azmoon Co.).

\subsection{Herbal Preparation and Extraction}

Kelussia odoratissima that grows at the heights of Zardkooh Bakhtiari was collected and recognized by a botanist, and was registered with the code of 245 in the Herbarium unit of the medical plant research center of Shahrekord university of medical sciences.

The percolation technique was used for extraction. The aerial parts of the plant were soaked in $80 \%$ methanol and then dried and powdered. Afterwards, they were transferred to a "percolator" and extraction was done at the temperature of $15-20^{\circ} \mathrm{C}$ with the help of $80 \%$ methanol. Before adding the powder to the percolator, a piece of "glass wool" was placed at its bottom.

Furthermore, 1000 gr of dried plant powder was placed in a beaker, and $80 \%$ methanol was added with amounts to cover the surface of the powder (in a way in that a 3.5 $\mathrm{cm}$ layer of methanol covered the surface of the powder). The mixture was added to the percolator after 24 hours and a filter paper was placed over it. After adding $80 \%$ methanol, the tap of percolator was set in a way that the rate of solvent flow was two to three drops per minute. The distillation of the extract was done under vacuum at a low temperature by a "rotary operator". The condensed extract was transferred to a "watch glass" and placed in the oven at 40 degrees centigrade for 72 hours to dry completely (59-61).

Considering that the sample volume was less than 30 mice $(n=14)$ in this research and the lipid observations did not follow normal distribution, non-parametric Kruskal-Wallis test was used for data analysis (62).

\section{Results}

The results showed that lipid factors including cholesterol, LDL, VLDL, HDL and FBS were significantly different in the intervention groups (extracts 10\% and 20\%) in comparison with the case (normal diet) and high cholesterol groups $(\mathrm{P}<0.05)$. The effect of the extract in decreasing cholesterol and LDL in the 10\% group was more than the $20 \%$ group $(\mathrm{P}<0.05)$. The mean cholesterol, TG, VLDL and FBS levels were more in the two groups of olive oil and high cholesterol in comparison with the case group (normal food) $(\mathrm{P}<0.05)$. The level of cholesterol was more in the high cholesterol compared to the olive oil group $(\mathrm{P}<$ 0.05). The reduction rate of TG, VLDL and FBS was statistically significant in the group receiving the 10\% extract in comparison with the high cholesterol group $(\mathrm{P}<0.05)$; however, this reduction was not significant in the group that received the $20 \%$ extract compared to the high cholesterol group $(\mathrm{P}>0.05)$. The two groups that received the $10 \%$ and $20 \%$ extracts did not have statistical significant differences in the reduction rate of TG and VLDL $(\mathrm{P}>0.05)$.

The mean HDL in the high cholesterol and olive oil groups showed a significant reduction in comparison with the case group $(\mathrm{P}<0.05)$, yet the difference between the high cholesterol and olive oil group was not statistically significant $(\mathrm{P}>0.05$; Table 1$)$.

The mean LDL/HDL ratio had a significant increase in the olive oil and high cholesterol groups in comparison with the case group and this increase was more significant in the high cholesterol group than the olive oil group. The mean LDL/HDL ratio had a significant decrease in groups that received the $10 \%$ and $20 \%$ extract compared to the olive oil and high cholesterol groups and this decrease was more significant in the group that received the $10 \%$ extract in comparison with the group that received the $20 \%$ extract of Kelussia odoratissima ( $\mathrm{P}<0.05$; Table 1$)$. 
Shahrani M et al.

Table 1. The Mean Level of Lipid and Blood Glucose of Mice in the Studied Groups at the End of the Two Weeks of Intervention a,b,c

\begin{tabular}{lccccccc}
\hline Group & \multicolumn{7}{c}{ Factor } \\
\cline { 2 - 8 } & FBS & Cholesterol & VLDL & Triglyceride & LDL & HDL & LDL/HDL \\
\hline Control (Group 1) & $144.71 \pm 15.12$ & $145.71 \pm 19.97$ & $39.54 \pm 10.69$ & $197.71 \pm 53.49$ & $52.59 \pm 17.80$ & $53.57 \pm 14.80$ & $1.09 \pm 0.57$ \\
Group 2 $^{\mathrm{d}}$ & $244.41 \pm 201.67$ & $299.23 \pm 184.89$ & $53.92 \pm 16.16$ & $269.64 \pm 80.84$ & $296.76 \pm 265.2$ & $9.46 \pm 9.56$ & $42.14 \pm 50.33$ \\
Group 3 $^{\mathrm{d}, \mathrm{e}}$ & $203.00 \pm 73.34$ & $282.5 \pm 82.23$ & $57.75 \pm 16.57$ & $288.78 \pm 82.89$ & $444.82 \pm 337.36$ & $9.14 \pm 0.53$ & $49.13 \pm 37.67$ \\
Group 4 $^{\mathrm{f}}$ & $107.21 \pm 17.31$ & $114.46 \pm 69.08$ & $45.42 \pm 25.35$ & $277.14 \pm 126.76$ & $64.96 \pm 56.13$ & $7.35 \pm 2.09$ & $8.92 \pm 7.17$ \\
Group 5 $^{\text {g }}$ & $225.76 \pm 57.33$ & $134.07 \pm 28.40$ & $45.98 \pm 48.56$ & $299.92 \pm 70.02$ & $78.93 \pm 27.60$ & $8.07 \pm 1.75$ & $10.82 \pm 7.08$ \\
\hline
\end{tabular}

a Abbreviations: FBS, fasting blood sugar; HDL, high density lipoprotein; LDL, low density lipoprotein; VLDL, very low density lipoprotein.

$\mathrm{b}$ Data are based on $\mathrm{mg} / \mathrm{dL}$ and in the form of mean $\pm \mathrm{SD}$.

c Group 1: the case group receiving normal food without any drug and extract; Group 2: receiving normal food including olive oil; Group 3: receiving high cholesterol food and olive oil; Group 4: receiving high cholesterol and hydro-alcoholic extract of Kelussia odoratissima Mozaffarian 10\%; Group 5: receiving high cholesterol food and Kelussia odoratissima Mozaffarian $20 \%$.

d $\mathrm{P}<0.05$ in comparison with "Group 1" in all factors.

e $\mathrm{P}<0.05$ in comparison with "Group 2" in all biochemical factors except cholesterol.

f $\mathrm{P}<0.05$ in comparison with "Group 1" in FBS (fasting blood sugar), cholesterol, HDL (high density lipoprotein) and LDL/HDL, and in comparison with "Group 2" in all factors except VLDL and TG, and in comparison with "Group 3" in all factors.

g $\mathrm{P}<0.05$ in comparison with "Group 1" in FBS, LDL (low density lipoprotein), HDL and LDL/HDL, and in comparison with "Group 2" in all factors except VLDL (very low density lipoprotein) and TG (triglyceride), and in comparison with "Group 3" in cholesterol, LDL HDL and LDL/HDL, and in comparison with "Group 4" in FBS and cholesterol.

During the study, the weight of mice increased in all groups except the group that received the $10 \%$ extract, yet this increase was not significant $(\mathrm{P}>0.05)$.

\section{Discussion}

In this animal study, the use of Kelussia odoratissima 10\% hydro-alcoholic extract caused a significant reduction in mean HDL, cholesterol, TG, VLDL, LDL/HDL ratio and FBS at the end of the second week in hyperlipidemic mice. However, for the $20 \%$ extract, the mean levels of cholesterol, LDL/HDL ratio and LDL were significantly reduced $(\mathrm{P}<$ 0.05). Moreover, in all groups except the group receiving Kelussia odoratissima 10\% extract, the weight of animals increased.

Different studies have shown that Kelussia odoratissima has flavonoid combinations (63). Fraction analysis of the total extract of the plant showed the routine existence of 3, 4, 7-trihydroxyflavone, caffeic acid and phthalide (63$65)$. Since the mentioned flavonoids are all in the form of aglycone, they have fast intestinal absorption due to their specific structure (66). Therefore, the lipid decrease was expected after the use of Kelussia odoratissima Mozaffarian. Antioxidant compounds decrease harmful lipids through inhibition of cholesterol biosynthesis. Cholesterol synthesis regulation is normally done by HMG-CoA. The conversion reaction of HMG-CoA to mevalonate takes place by the mediation of HMG-CoA reductase and NADPH (Nicotine amide adenine dinucleotide phosphate) (67). The beneficial effect of Kelussia odoratissima was observed with reducing lipids in hypercholesterolemic mice in the laboratory.

The decrease of HDL in the animal test can be due to the increased cholesterol and LDL due to consuming highcholesterol food. The LDL/HDL ratio decreased in animal tests. This ratio is highly significant in predicting the rate of coronary diseases. This relationship can be justified with the roles suggested for LDL in transferring cholesterol to tissues and the role of HDL in the reverse transfer of cholesterol (68).

In this study, taking the extract of Kelussia odoratissima caused a significant decrease in lipid factors in mice. Therefore, performing human studies on the effect of normal antioxidants and especially Kelussia odoratissima on patients with lipid and glucose of hyperlipidemia seems necessary. It should be noted that the exact mechanism of of garlic extract is not clear. If antioxidant property of the plant is a main factor, hence other plants with antioxidant activity $(69,70)$ may have the same effect, thich worth examining.

\section{Acknowledgements}

This paper was derived from the MSc thesis of A. Asgari and financially supported by the research deputy of Shahrekord university of medical sciences.

\section{Financial Disclosure}

This paper was financially supported by the research deputy of Shahrekord university of medical sciences.

\section{Funding/Support}

This paper was derived from the MSc thesis of A. Asgari and financially supported by the research deputy of Shahrekord university of medical sciences.

\section{References}

1. Jain KS, Kathiravan MK, Somani RS, Shishoo CJ. The biology and chemistry of hyperlipidemia. Bioorg Med Chem. 2007; 15(14):4674-99.

2. Setorki M, Rafieian-Kopaei M, Merikhi A, Heidarian E, Shahinfard 
$\mathrm{N}$, Ansari R, et al. Suppressive impact of anethum graveolens consumption on biochemical risk factors of atherosclerosis in hypercholesterolemic rabbits. Int J Prev Med. 2013;4(8):889-95.

3. Rafieian-Kopaei M, Setorki M, Doudi M, Baradaran A, Nasri H. Atherosclerosis: process, indicators, risk factors and new hopes. Int J Prev Med. 2014;5(8):927-46.

4. Wong Bun Lap B. Hypercholesterolemia: a guide to clinical prac tices bulletin. Hong Kong Med Assoc CME Bull. 2004:1-9.

5. Kishor S, Jain MK, Kathiravan RS. The biology and chemistry of hyperlipidemia. Bioorg Med Chem. 2007;15:674-820.

6. Shirzad H, Nasri H. Toxicity and safety of medicinal plants.J Herb Med Pharmacol . 2014;2(2).

7. Hajivandi A, Amiri M. World diabetes day: diabetes mellitus and nephrology. J Nephropharmacol. 2013;2(2):31-2.

8. Rahimi Z, Moradi M, Nasri H. A systematic review of the role of renin angiotensin aldosterone system genes in diabetes mellitus, diabetic retinopathy and diabetic neuropathy. J Res Med Sci. 2014;19(11):1090-8.

9. Nasri H, Yazdani M. The relationship between serum LDL-cholesterol, HDL-cholesterol and systolic blood pressure in patients with type 2 diabetes. Kardiol Pol. 2006;64(12):1364-8.

10. Kafeshani M. Ginger, micro-inflammation and kidney disease. J Renal Endocrinol. 2015;1(1):e04.

11. Rafieian-Kopaei M, Baradaran A, Rafieian M. Plants antioxidants: From laboratory to clinic. J Nephropathol. 2013;2(2):152-3.

12. Ardalan MR, Khodaie L, Nasri H, Jouyban A. Herbs and hazards: risk of aristolochic acid nephropathy in Iran. Iran J Kidney Dis. 2015;9(1):14-7.

13. Rafieian-Kopaei M, Hosseini M, Shirzad H. Comment on: effect of pomegranate flower extract oncis platin-induced nephrotoxicity in rats. J Nephropathol. 2014;3(4):121-3.

14. Nasri H, Baradaran A, Shirzad H, Rafieian-Kopaei M. New concepts in nutraceuticals as alternative for pharmaceuticals. Int $J$ Prev Med.2014;5(12):1487-99.

15. Sotodeh-Asl N, Tamadon MR, Malek F, Zahmatkesh M. Vitamin D deficiency and psychological disorders. J Parathyr Dis. 2015;2(1).

16. Rafieian-Kopaei M, Sewell RDE. The history and ups and downs of herbal medicines usage. J HerbMed Pharmacol. 2014;3(1):1-3.

17. Tavafi M. Diabetic nephropathy and antioxidants. J Nephropathol. 2013;2(1):20-7.

18. Nasri H, Shahinfard N, Rafieian M, Rafieian S, Shirzad M, Rafieian M. Turmeric: A spice with multifunctional medicinal properties. J Herbmed Med Pharmacol. 2014;3(1).

19. Lala MA, Nazar CMJ, Lala HA, Singh JK. Interrelation between blood pressure and diabetes. J Renal Endocrinology. 2015;1(1):e05.

20. Rafieian-Kopaei M, Baradaran A, Merrikhi A, Nematbakhsh M, Madihi Y, Nasri H. Efficacy of Co-administration of Garlic Extract and Metformin for Prevention of Gentamicin-Renal Toxicity in Wistar Rats: A Biochemical Study. Int J Prev Med. 2013;4(3):258-64.

21. Khajehdehi P. Turmeric: Reemerging of a neglected Asian traditional remedy. J Nephropathol. 2012;1(1):17-22.

22. Nasri H, Rafieian-Kopaei M. Effect of vitamin D on insulin re sistance and nephropathy in type 2 diabetes. $J$ Res Med Sci. 2014;19(6):581-2.

23. Baradaran A, Nasri H, Rafieian-Kopaei M. Protection of renal tubular cells by antioxidants: current knowledge and new trends. Cell J. 2015;16(4):568-71.

24. Motamedi F, Nematbakhsh M, Monajemi R, Pezeshki Z, Talebi A Zolfaghari B, et al. Effect of pomegranate flower extract on cisplatin-induced nephrotoxicity in rats. J Nephropathol. 2014;3(4):133-8.

25. Nasri H, Nematbakhsh M, Ghobadi S, Ansari R, Shahinfard N Rafieian-Kopaei M. Preventive and curative effects of ginger extract against histopathologic changes of gentamicin-induced tubular toxicity in rats. Int J Prev Med. 2013;4(3):316-21.

26. Baradaran A, Nasri H, Nematbakhsh M, Rafieian-Kopaei M. Antioxidant activity and preventive effect of aqueous leaf extract of Aloe Vera on gentamicin-induced nephrotoxicity in male Wistar rats. Clin Ter. 2014;165(1):7-11.

27. Mardani S, Nasri H, Hajian S, Ahmadi A, Kazemi R, Rafieian-Kopaei M. Impact of Momordica charantia extract on kidney function and structure in mice. J Nephropathol. 2014;3(1):35-40.

28. Mirhosseini M, Baradaran A, Rafieian-Kopaei M. Anethum grave- olens and hyperlipidemia: A randomized clinical trial. J Res Med Sci. 2014;19(8):758-61.

29. Nasri H, Madihi Y, Marikhi A. Commentary on: Effects of Cinnamon Consumption on Glycemic Status, Lipid Profile and Body Composition in Type 2 Diabetic Patients. Int J Prev Med. 2013;4(5):618-9.

30. Rafieian-Kopaei M, Motamedi P, Vakili L, Dehghani N, Kiani F, Taheri Z, et al. Green tea and type 2 diabetes mellitus. J Nephropharmacol. 2015;3(1).

31. Nasri H. Re: effect of silymarin on streptozotocin-nicotinamideinduced type 2 diabetic nephropathy in rats. Iran J Kidney Dis. 2013;7(5):414-5.

32. Ardalan MR, Sanadgol H, Nasri H, Baradaran A, Tamadon MR, Rafieian Kopaei M. Vitamin D therapy in diabetic kidney disease; current knowledge on a public health problem. J Parathyr 2015;2(1).

33. Nasri H, Behradmanesh S, Ahmadi A, Rafieian-Kopaei M. Impact of oral vitamin $\mathrm{D}$ (cholecalciferol) replacement therapy on blood pressure in type 2 diabetes patients; a randomized double-blind, placebo controlled clinical trial. J Nephropathol. 2014;3(1):29-33.

34. Mirhoseini M, Baradaran A, Rafieian-Kopaei M. Medicinal plants, diabetes mellitus and urgent needs. J Herbmed Med Pharmacol. 2014;2(2).

35. Nasri H, Shirzad H, Baradaran A, Rafieian-kopaei M. Antioxidant plants and diabetes mellitus. J Res Med Sci. 2015;20(5):1-12.

36. Rafieian-Kopaei M, Baradaran A. On the occasion of world diabetes day 2105; act today to change tomorrow. J Renal Endocrinol. 2015;1(1).

37. Nasri H, Rafieian-Kopaei M. Protective effects of herbal antioxidants on diabetic kidney disease. J Res Med Sci. 2014;19(1):82-3.

38. Nasri H, Rafieian-Kopaei M. Comment on: The effects of green tea consumption on metabolic and anthropometric indices in patients with type 2 diabetes. J Res Med Sci. 2014;19(12):1203-4

39. Ardalan MR, Rafieian-Kopaei M. Antioxidant supplementation in hypertension. J Renal Inj Prev. 2014;3(2):39-40.

40. Baradaran A, Nasri H, Rafieian-Kopaei M. Oxidative stress and hypertension: Possibility of hypertension therapy with antioxidants. J Res Med Sci. 2014;19(4):358-67.

41. Nasri H, Ardalan MR, Rafieian-Kopaei M. On the occasion of world hypertension day 2014: A nephrology point of view. J Res Med Sci. 2014;19(9):911-2.

42. Tavafi M. Antioxidants against contrast media induced nephrotoxicity. J Renal Inj Prev. 2014;3(2):55-6.

43. Nasri H. Antioxidants for prevention of gentamicin-induced nephrotoxicity. Iran J Kidney Dis. 2014;8(1):1-2.

44. Hajian S, Rafieian-Kopaei M, Nasri H. Renoprotective effects of antioxidants against cisplatin nephrotoxicity. J Nephropharmacol. 2014;3(2):39-42.

45. Nasri H, Ahmadi A, Baradaran A, Nasri P, Hajian S, Pour-Arian A et al. A biochemical study on ameliorative effect of green tea $\mathrm{Ca}$ mellia sinensis) extract against contrast media induced acute kidney injury. J Renal Inj Prev. 2014;3(2):47-9.

46. Nasri H, Nematbakhsh M, Rafieian-Kopaei M. Ethanolic extract of garlic for attenuation of gentamicin-induced nephrotoxicity in Wistar rats. Iran J Kidney Dis. 2013;7(5):376-82.

47. Sadeghi F, Nematbakhsh M, Noori-Diziche A, Eshraghi-Jazi F, Talebi A, Nasri $\mathrm{H}$, et al. Protective effect of pomegranate flower extract against gentamicin-induced renal toxicity in male rats. $J$ Renal Inj Prev. 2015;4(2):45-50.

48. Bagheri N, Azadegan-Dehkordi F, Sanei H, Taghikhani A, Rahimian G, Salimzadeh L, Hashemzadeh-Chaleshtori M, Rafieiankopaei M, Shirzad M, Shirzad H. Associations of a TLR4 singlenucleotide polymorphism with $\mathrm{H}$. pylori associated gastric diseases in Iranian patients. Clin Res Hepatol Gastroenterol. 2014;38(3):35-41.

49. Mozaffarian V. Two new genera of Iranian Umbelliferae. Bot Zhurn. 2003;88:88-94.

50. Shojaei Asadiyeh Z, Ebrahimi A, Salimi M. Chemical composition of three ecotypes of wild celery (Kelussia odoratissima). J Herbs Spices Med Plant. 2011;17(1):62-8.

51. Ghasemi PA. Medicinal plants used in Chaharmahal and 
Shahrani M et al.

Bakhtyari districts of Iran. Herb Pol. 2009;55(2):69-77.

52. Mozaffarian V. A dictionary of Iranian plant names.Tehran: Farahang Moaser; 1996.

53. Ahmadi F, Kadivar M, Shahedi M. Antioxidant activity of Kelussia odoratissima Mozaff. in model and food systems. Food Chem. 2007;105(1):57-64.

54. Rabbani M, Sajjadi SE, Sadeghi M. Chemical composition of the essential oil from kelussia odoratissima Mozaff. and the evaluation of its sedative and anxiolytic effects in mice. Clinics (Sao Paulo). 2011;66(5):843-8.

55. Kaufman PB, Cseke LJ, Warber S, Duke JA, Brielmann HL. Natural products from plants.New York: CRC Press; 1999.

56. Omidbaigi R, Sefidkon F, Saeedi K. Essential Oil Content and Composition ofKelussia odoratissimaMozaff. as an Iranian Endemic Plant. J Essent Oil Bearing Plants. 2008;11(6):594-7.

57. Kuang X, Du JR, Liu YX, Zhang GY, Peng HY. Postischemic administration of Z-Ligustilide ameliorates cognitive dysfunction and brain damage induced by permanent forebrain ischemia in rats. Pharmacol Biochem Behav. 2008;88(3):213-21.

58. Song ZH, Ji ZN, Lo CK, Dong TT, Zhao KJ, Li OT, et al. Chemical and biological assessment of a traditional chinese herbal decoction prepared from Radix Astragali and Radix Angelicae Sinensis: orthogonal array design to optimize the extraction of chemical constituents. Planta Med. 2004;70(12):1222-7.

59. Aynehchi Y. [Pharmacognosy and medicinal plant].Tehran: University Press Center; 1986.

60. Zargare A. .[Medicinal plant].Tehran: University Center Press; 1992.
61. Samsam Shariat H. [Medicinal plant propagation].Tehran: Mani Pub; 1990.

62. Conover WJ. [Practical nonparametric statistics] Translatedby: $\mathrm{Ha}$ shame Parast,.Tehran: University Center Press; 1980.

63. Gandomcar M. [Survey organic oil of Amirkabiria odoratissima Mozaffarian. General PhD pharmacology disertation]. Isfahan Univ Med Sci. 2008;2-4(38).

64. Dadkhahi Z. . Survey of Amirkabiria odoratissima Mozaffarian General PhD pharmacology disertation.. Isfahan Univ Med Sci; 2008.

65. Harbrone JB. The flavonoids advance in research science.London: Chapman and Hall; 1994.

66. Kerry N, Rice-Evans C. Peroxynitrite oxidises catechols to o-quinones. FEBS Lett.1998;437(3):167-71.

67. Asgary S, Naderi G, Dashti G, Paknahad Z. Effect of Amirkabiria odorastissima Mozaffarian on the development and progression of fatty streaks in hypercholesterolemic rabbits. Phytother Res. 2004;18(5):370-2.

68. Ness GC, Holland RC. Degradation of HMG-CoA reductase in rat liver is cholesterol and ubiquitin independent. FEBS Lett. 2005;579(14):3126-30.

69. Shirani M, Alibabaei Z, Kheiri S, Shirzad H, Taji F, Asgari A, Rafieian M. Effect of Euphorbia helioscopia extract on acute and chronic pain in mice. J Babol Univ Med Sci 2011;13(4):14-18.

70. Bahmani M, Zargaran A, Rafieian-Kopaei M, Saki M. Ethnobotanical study of medicinal plants used in the management of diabetes mellitus in the Urmia, Northwest Iran. Asian Pac J Trop Med 2014;7(Suppl 1):348-354. 